\title{
Eating disorders: need for a broader assessment
}

\author{
Transtornos alimentares: necessidade de uma avaliação mais ampla
}

Rodolfo Nunes Campos*

Eating disorders are associated with notable severity and disability. In addition, they represent a public health concern in view of their frequent relationship with other psychiatric disorders, and often receive inappropriate treatment. The high morbidity and mortality associated with both poor nutrition and suicidal behavior highlight the need to expand the knowledge of causes, associated features, and consequently treatment of these conditions.

Although eating disorders are traditionally considered as a less common type of psychiatric condition, epidemiological studies have shown that their occurrence may be underestimated. Prevalence rates range from 0.5 to $3.7 \%$ for anorexia nervosa (AN) and from 1.1 to $4.2 \%$ for bulimia nervosa (BN), ${ }^{1}$ and they increase when incomplete manifestations of the syndromes are taken into account: $2.4 \%$ for partial AN (without amenorrhea), $2.9 \%$ for binge eating disorder, and $5.3 \%$ for purging disorder without binge. ${ }^{2}$ Long-term studies indicate that about one third of the patients with AN present only a partial improvement of symptoms, whereas $20 \%$ remain chronically ill. ${ }^{3}$

It is believed that social, psychological and biological causes are related to eating disorders. According to the psychodynamic perspective, there are several mechanisms associated with altered eating behavior; in this scenario, the patients' relationships with their parents play a key role. In this issue of Trends in Psychiatry and Psychotherapy, Campos et al. describe recurrent characteristics of patients with AN with regard to motherdaughter relationships, with emphasis on the issue of mutual control and the dialectic between omnipotence and impotence, which may be important targets for interventions. ${ }^{4}$

One previous study of ours designed to evaluate patients with eating disorders treated at a tertiary center showed that this population is clinically severe and that comorbidity with other psychiatric disorders is the rule, especially mood and substance use disorders. ${ }^{5}$ This is a population with a complex phenomenology involving the distortion of body image, impulsivity, and impaired social adjustment requiring an approach that addresses these facets.

We are heading towards a refinement of the therapeutic approaches available to this population. Future research needs to include extensive clinical evaluation of the various aspects involved in eating disorders, such as the underlying biological changes or psychodynamic characteristics of family relationships in these families.

\footnotetext{
* Doutor em Psiquiatria, Faculdade de Medicina, Universidade de São Paulo (USP), São Paulo, SP, Brazil. Professor colaborador, Departamento de Psiquiatria, Faculdade de Medicina, Universidade Federal de Goiás (UFGO), Goiânia, GO, Brazil. E-mail: rodolfoncampos@hotmail.com No conflicts of interest declared concerning the publication of this editorial.

Suggested citation: Campos RN. Eating disorders: need for a broader assessment. Trends Psychiatry Psychother. 2012;34(1):3-4.
} 


\section{References}

1. Pinzon V, Nogueira FC. Epidemiologia, curso e evolução dos transtornos alimentares. Rev Psiquiatr Clin. 2004;31:158-60.

2. Wade TD, Crosby RD, Martin NG. Use of latent profile analysis to identify eating disorder phenotypes in an adult Australian twin cohort. Arch Gen Psychiatry. 2006;63:137784.

3. Steinhausen HC. The outcome of anorexia nervosa in the 20th century. Am J Psychiatry. 2002;159:1284-93.
4. Campos LK, Sampaio AB, Garcia Jr C, Magdaleno Jr R, Battistoni MM, Turato ER. Psychological characteristics of mothers of patients with anorexia nervosa: implications for treatment and prognosis. Trends Psychiatry Psychother. 2012;34:13-8.

5. Campos RN. Ocorrência e correlatos do espectro bipolar em pacientes com transtornos alimentares atendidos em serviço terciário: Projeto ESPECTRA [tese]. São Paulo; Universidade de São Paulo; 2011. 